\title{
Pattern Design and Embroidery Based on the Intelligent System
}

\author{
Yingxia Lin, Yujie Wu*, Lei Hao, Yi Wu, Huixin Chi and Yuanyuan Chen \\ School of Information Engineering, Beijing Institute of Fashion Technology, Beijing, China \\ ${ }^{*}$ Corresponding author
}

\begin{abstract}
Embroidery is a kind of world-wide art with a long history and a splendid culture. Crafts-making of the embroidery in China can be traced back to over 3,000 years to ancient times. However, modern techniques for creative embroidery is characterized by using embroidery machine instead of traditional crafts. This paper briefly is devoted to design and fabrication of the embroidered works on intelligent embroidery machines. Due to high precision and efficiency, intelligence control techniques have greatly promoted the production efficiency and the personalized customization of the embroidery products. There are sections in this paper, which are the introduction, the basic workflow of the design and manufacture, the embroidery pattern design of digital processing, the simulation experiments and the conclusion.
\end{abstract}

Keywords-intelligent embroidery; pattern design, computer aided design

\section{INTRODUCTION}

As one of the excellent national traditional crafts in china, embroidery is also called silk embroidery. More than 5,000 years ago, reeling and rearing silkworms had become popular in China .The silk production and trade flourished after the opening of the Silk Road in the Han dynasty. In the 14th century, the Chinese silk embroidery production reached its high peak. Several major silk embroidery styles had been developed, like Song Jin in Suzhou, Yun Jin in Nanjing and Shu Jin in Sichuan. Some of the basic techniques or stitches of the earliest embroidery are chain stitch, buttonhole or blanket stitch, running stitch, satin stitch, cross stitch, cross-stitch embroidery, nail wire embroidery, plain embroidery and so on. Exquisite embroidery works are popular among people all over the world. But the production efficiency is low, cannot meet the market demand. Elaborately embroidered clothing, religious objects, and household items only spread in polite society.

With the development of the industrial revolution, Machine embroidery and its mass production are developing gradually. The earliest machine embroidery used a combination of machine looms and teams of women embroidering the textiles by hand. There are various types of machine embroidery. Free-motion sewing machine embroidery uses a basic zigzag sewing machine. Designs are completed by hand. Compared with the traditional hand embroidery, free-motion machine embroidery is more efficient, free-motion machine embroidery was once popular with all over the world.
With the development the economy and culture, the disadvantages of the free-motion machine embroidery have become prominent gradually. Since a standard sewing machine has only one needle and it must also manually trimmed and cleaned up loose threads after the design is completed, the operator must turn off the machine. In addition, as this is a manual process rather than a digital reproduction, any pattern created using free-motion machine embroidery is unique and cannot be exactly reproduced, computerized machines embroidery came into being.

Take computer sewing machine as the prototype and with the development of electronics, computer technology and precision machinery, the intelligent embroidery machine that comes into being has made Chinese traditional embroidery technology intellectualized .Compared with the machine embroidery. Modern embroidery machines process higher production efficiency but also have the finest of traditional handmade embroidery work. A multi-needle machine may consist of multiple sewing heads, each of which can sew the same design onto a separate garment concurrently. Last but not the least, it realized the diversification and individuation of embroidery pattern, satisfying people's pursuit of beauty and improving people's living standard.

The history of machine embroidery can be traced back to 1964, Tajima started to manufacture and sell embroidery machines. In 1980, computerized embroidery machines were introduced into the domestic market for the first time. After the Brother Industry entered the embroidery industry, several computerized embroidery companies contracted it to provide sewing heads. Pulse Microsystems developed a software for them, called PG1. From then on, China began to advance computerized machines embroidery nenergetically.

Take Rich peace brand embroidery machine as an example, the embroidery pattern designed by computer aided design combined with the mechanical and electrical components of the computer embroidery machine, to realize the functions of detection of broken line, back and reembroidered, automatic color change, automatic clipping, pattern storage, the conversion of patterned coordinate limit detection, automatic repeated embroidery and so on, so it can automatically complete an exquisite embroidery.

\section{BASIC WORKFLOW OF THE DESIGN AND MANUFACTURE}

First of all, design and edit a digitized embroidery pattern file that works with the brand of machine. Then load the right 
format file into the embroidery machine and it will file in the appropriate hoop.

The mechanical aspects of computer embroidery machine can be divided into frame, embroidery, color changing, frame moving, the hook, the cutting, and the knot and so on. Among them, the embroidery and the frame moving are the most essential, which independently and harmoniously completed the embroidery. In order to accomplish a beauteous embroidery work, needle bar drives the needle and thread to move, the frame is reciprocating in the plane $\mathrm{X}$ and $\mathrm{Y}$ direction[1].

The basic work flows as shown.

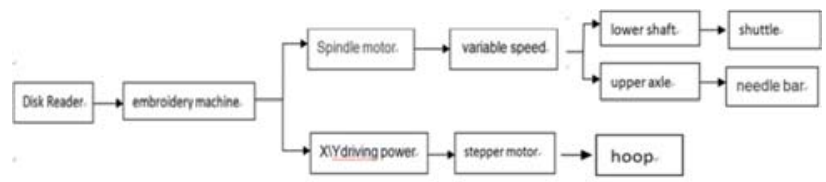

FIGURE I. BASIC WORK FLOW

\section{EMBROIDERY PATTERN DESIGN OF DIGITAL PROCESSING}

\section{Ready for digitization}

Analyzing and planning the order of the pattern design shapes and embroidery stitches before starting to digitize.

\section{Digitize manually}

Manual digitization can create a pattern design from a basic shape or "embroidered object." Different tools are available for creating different shape or pattern design elements. Once selected the appropriate tool then by marking the reference points along the outline to "digitize" digital technology.

\section{Professional digital technology}

This software provides specialized digital skills to save time and produce special effects and machine functions. To provide the digital mosaic embroidery, stars, branches and other specialized input tools. There are also specialized ways of adding contours, embroideries, and deepening of contours. Using the software to digitize these effects to add towel embroidered or sequined. The embroideries are extracted from the pattern design for export to the cutter or for export to separate files. The cross stitches also can be used to embroider large areas with low stitches.

\section{Computer Aided Design}

Through the linear, banding, regional input methods realized the intellectualization of computer embroidery

It combines with creativity, styling, plate-making and simulation, as a result, the traditional digital technology and editing methods are combined with advanced graphics processing technology, which greatly enhances the ability of software to create, edit, process and manage pattern designs .Based on the resourceful embroidery knowledge, automatic needle filling technique and repository can make any drawings be completed perfectly.
According to the pattern to choose the right method of needle the most common methods are Creeding Stitch, See fill Stitch

Tatami stitch and Cross-Stitch. And based on the side of the input, bilateral input and the center input, so that the angle of stitch can rotate evenly, fill the needle line coordinate with the linear input of automatic single needle and manual single needle to avoid the emergence of the broken line and improve the efficiency of production ${ }^{[2]}$.

\section{The intelligent sewing of drawings}

Computerized embroidery is also known as playing with a tape, refers to the card, tape or plate or through the number of processes such as preparation to prepare patterns to guide or stimulate embroidery machine and embroidery frame for the design of the various sports process. The designer of this process is a pattern master. The term comes from the mechanical embroidery machine by punching the tape to record stitches derived. Whether mechanical or electronic embroidery machines, the purpose of stitching is to allow the embroidery machine to recognize and perform its actions, possibly with a needle attached to a horizontal and vertical bar, using a mechanical or mouse or more modern Way to record those who need to form a pattern of points ${ }^{[4]}$.

The basic steps for creating embroidery with a computerized embroidery machine are as follows:

- There are 3 kinds of tools: computerized embroidery machine, embroidery plate making software, and a U disk.

- The first step: The design of embroidery patterns, also known as plate making. In the work of the staff called plate making division. Designers can easily apply those software to design patterns, after the design, save the pattern to the computer fixed disk.

- The second step: Finding the embroidery pattern file and opened it. Changing files to suffix DST files. (Computerized embroidery machine can only recognize. DST files).

- The third step: Put the file into the computer embroidery machine, and click "Enter files into memory" which the control button on the panel of the computerized embroidery machine.

- The fourth step: Positioning. Move the embroidery frame up and down until the position is right, click the "embroidery confirmation button" .This will determine the origin of the embroidery.

- Enter the embroidery color, and start embroidering.

- During the actual production process, due to various factors (such as lack of the needle and thread) lead to the lack of part of the stitch. Take advantages of the functions of detection of broken line, back and re-embroidered, to complete the embroidery works ${ }^{[3]}$. 


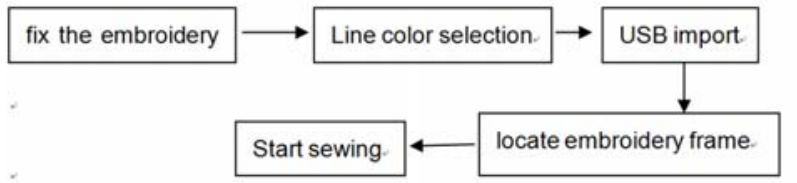

FIGURE II. MANUFACTURING PROCESS

\section{SIMULATION EXPERIMENTS}

In this section, four works are presented. The first work is titled by ambitious and innovation. In the embroidery, some characters which are the initials of Beijing institute of fashion are wrapped around by flowers. This implies that at the beautiful times we undergraduates meet at Beijing institute of fashion, and grow healthily in the arms of Beijing institute of fashion. In the future, we will repay our university with splendid achievements, and adorn Beijing institute of fashion's cultivation.

The second work is titled by renewal. The pattern of this work is inspired by human skeleton and flowing blood. It symbolizes the constant exploration and growth of life, just like blood spreading over all parts of the body. Combining with the transparent, textured fabric, this pattern make the vision more meaningful. In the whole embroidering process flat needles with $0.7 \mathrm{~mm}$ needle distance are needed.

The third work is Givenchy manuscript. Givenchy is a fashion brand from France, which logo is a combination of four concepts, classical (Genteel), elegant (Grace), pleasure (Gaiety), and Givenchy. Givenchy manuscripts are applied to the prototype in the embroidery design, which mainly aims to pass on immortal pursuit of art, as the fashion industry for decades has been "elegant style" known to the world Givenchy with its chic and delicate attitude of the impact of the session of the fashion icon. This piece of work is in the greatest impact on the fashion industry, since the little black dress has once been the requisite fashion product for ladies. This classic work, in the form of Chinese embroidery, has a stronger Chinese flavor and is very attractive. Embroidery process is conducted by comprehensive application of multiple technologies such as single needle, bilateral, side, tatami and so on.

The fourth work is titled by loveliness to portray cute looks and cute human, where the sweet smile is available.

The fifth work is devoted to show the beauty of Chinese character writing with various font and size through embedding a traditional ancient Chinese poetry in it.

The sixth work is a figure of little fox, which is the integrated effect of stitch such as flat embroidery, flat-coated needle, tatami, single-pin and pin. In this works Spiraea are in seven different colors; another color is interpolated to the fox face to create elaborate color gradients. Around the fox pattern is an embroidered circle, and the branch pattern is inlaid with golden fruits, which make the entire composition of embroidery abundant in details. Simulation results are shown in Fig.3.

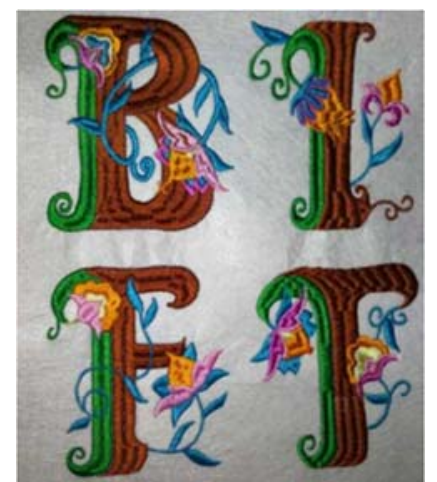

(1)
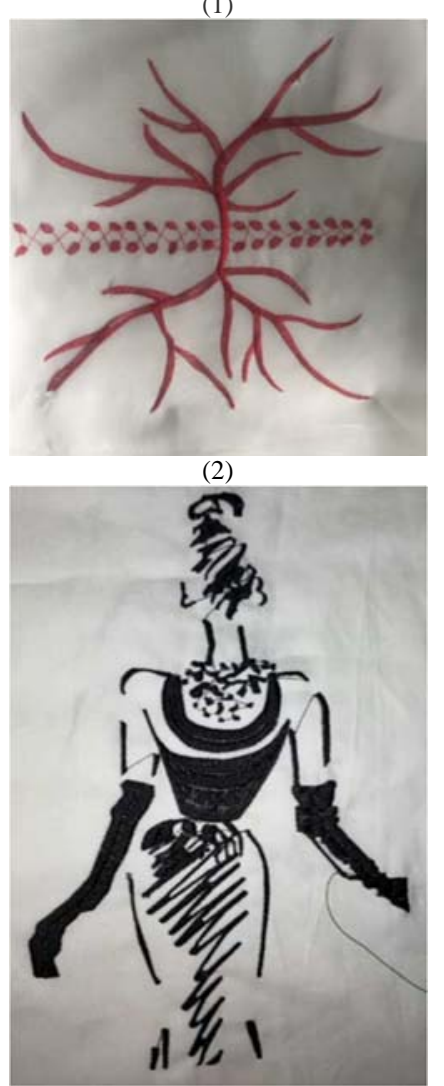

(3)

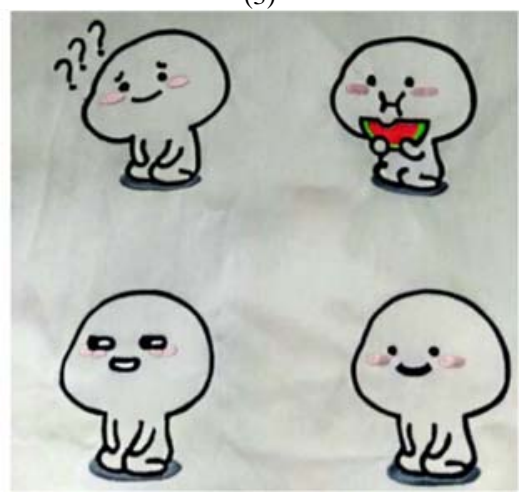

(4) 


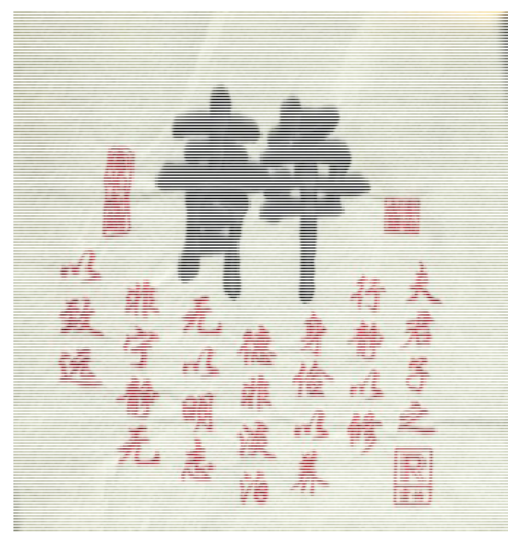

(5)

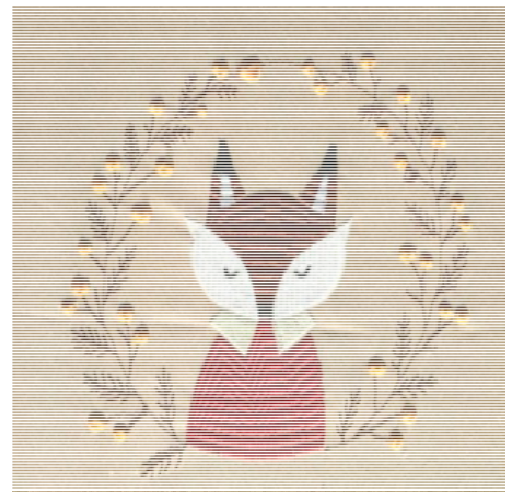

(6)

FIGURE III. SIMULATION RESUTLS

\section{CONCLUSION}

Computer Aided Design combined with embroidery machines, not only improve the production efficiency and quality of embroidery, reduce labor and production costs, but also rich the type of embroidery, promote the development of human civilization and to carry forward China's traditional embroidery.

\section{Acknowledgement}

This paper is supported by the key project of educational reform of Beijing Institute of Fashion Technology with granted No.ZDJG-1506.

\section{References}

[1] Xi-lin CAO, Zhi-jun LV. Brief analysis of mechanical principle of embroidery machine. Mechanical Management and Development, 2001, (S1): 4-5. [2017-09-17]. DOI:10.16525/j.cnki.cn14-1134/th.2001.s1.003

[2] Yun-tao LIU, Teaching courseware

[3] Yan-wen ZHAO, Shi-lin WU, Xiao-chu FANG. Work principle of Rich peace embroidery machine. Journal of Wuhan textiles \&T. institute Vo1.13 No.2 Jun.2000

[4] User manual of intelligent embroidery printing software. 